\title{
Recovery from hypoxemia and Hypercapnia following noninvasive pressure support ventilation in a patient with statin- associated necrotizing myopathy: a case report
}

Yuriko Yamamura ${ }^{1}$, Yoshinori Matsumoto ${ }^{1 *}$, Koh Tadokoro², Yasuyuki Ohta², Kota Sato², Toru Yamashita², Masahiro Yamamura ${ }^{3}$, Ken-Ei Sada ${ }^{1}$, Koji Abe $^{2}$ and Jun Wada ${ }^{1}$

\begin{abstract}
Background: Statin-associated necrotizing myopathy (SANM) is a rare autoimmune disorder caused by administration of statins. SANM is characterized by weakness due to necrosis and regeneration of myofibers. Here we report the first case of SANM with acute respiratory failure treated with noninvasive pressure support ventilation in addition to immunosuppressants.

Case presentation: A 59-year-old woman who had been treated with $2.5 \mathrm{mg} /$ day of rosuvastatin calcium for 5 years stopped taking the drug 4 months before admission to our hospital due to elevation of creatine kinase (CK). Withdrawal of rosuvastatin for 1 month did not decrease the level of CK, and she was admitted to our hospital due to the development of muscle weakness of her neck and bilateral upper extremities. Anti-3-hydroxy-3-methylglutaryl coenzyme A reductase antibodies were positive. Magnetic resonance imaging showed myositis, and muscle biopsy from the right biceps brachii muscle showed muscle fiber necrosis and regeneration without inflammatory cell infiltration, suggesting SANM. After the diagnosis, she received methylprednisolone pulse therapy (mPSL, $1 \mathrm{~g} /$ day $\times 3$ days, twice) and subsequent oral prednisolone therapy (PSL, $30 \mathrm{mg} /$ day for 1 month, $25 \mathrm{mg} /$ day for 1 month and $22.5 \mathrm{mg} /$ day for 1 month), leading to improvement of her muscle weakness. One month after the PSL tapering to $20 \mathrm{mg} /$ day, her muscle weakness deteriorated with oxygen desaturation (SpO2: 93\% at room air) due to hypoventilation caused by weakness of respiratory muscles. BIPAP was used for the management of acute respiratory failure in combination with IVIG $(20 \mathrm{~g} /$ day $\times 5$ days) followed by mPSL pulse therapy ( $1 \mathrm{~g} /$ day $\times 3$ days), oral PSL ( $30 \mathrm{mg} /$ day $\times 3$ weeks, then tapered to $25 \mathrm{mg} /$ day) and tacrolimus ( $3 \mathrm{mg} /$ day). Twenty-seven days after the start of BIPAP, she was weaned from BIPAP with improvement of muscle weakness, hypoxemia and hypercapnia. After she achieved remission with improvement of muscle weakness and reduction of serum CK level to a normal level, the dose of oral prednisolone was gradually tapered to $12.5 \mathrm{mg} /$ day without relapse for 3 months.

(Continued on next page)
\end{abstract}

\footnotetext{
* Correspondence: ymatsumoto@okayama-u.ac.jp

'Department of Nephrology, Rheumatology, Endocrinology and Metabolism,

Okayama University Graduate School of Medicine, Dentistry and

Pharmaceutical Sciences, Okayama 700-8558, Japan

Full list of author information is available at the end of the article
}

(C) The Author(s). 2020 Open Access This article is licensed under a Creative Commons Attribution 4.0 International License, which permits use, sharing, adaptation, distribution and reproduction in any medium or format, as long as you give appropriate credit to the original author(s) and the source, provide a link to the Creative Commons licence, and indicate if changes were made. The images or other third party material in this article are included in the article's Creative Commons licence, unless indicated otherwise in a credit line to the material. If material is not included in the article's Creative Commons licence and your intended use is not permitted by statutory regulation or exceeds the permitted use, you will need to obtain permission directly from the copyright holder. To view a copy of this licence, visit http://creativecommons.org/licenses/by/4.0/ The Creative Commons Public Domain Dedication waiver (http://creativecommons.org/publicdomain/zero/1.0/) applies to the data made available in this article, unless otherwise stated in a credit line to the data. 
(Continued from previous page)

Conclusions: Our report provides new insights into the role of immunosuppressants and biphasic positive airway pressure for induction of remission in patients with SANM.

Keywords: Noninvasive pressure support ventilation, Statin-associated necrotizing myopathy, BIPAP

\section{Background}

Statin-associated necrotizing myopathy (SANM), characterized by symmetrical weakness and muscle enzyme elevations as a consequence of necrosis and regeneration of myofibers, is a rare disease that occurs in patients treated with statins [1-3]. Previous studies suggested that statins enhance the expression of 3-hydroxy-3-methylglutaryl coenzyme A reductase (HMGCR), the enzymatic target of statins, in genetically susceptible patients, leading to the development of disease-specific antibodies against HMGCR [4-9]. SANM causes life-threatening hypoventilationmediated hypoxemia and hypercapnia, but therapeutic strategies for SANM have not been established yet.

Noninvasive pressure support ventilation (NIPSV) is the delivery of mechanical ventilation to the lungs without an endotracheal airway by biphasic positive airway pressure (BIPAP) that is applied with two levels of pressure, inspiratory positive airway pressure (IPAP) and expiratory positive airway pressure (EPAP) [10]. The patient's inspiratory effort triggers the ventilator to deliver a decelerated flow to achieve and maintain a preset pressure, while ventilatory assistance ceases when the patient's inspiratory flow falls. This modality is useful for patients with hypoxemia and/or hypercapnia due to acute respiratory failure, leading to a reduction of the intubation rate and mortality.

Here we report the first serious case of SANM complicated with hypoxemia and hypercapnia. Combined medications of glucocorticoids, immunosuppressants and intravenous immunoglobulins (IVIG) in addition to ventilatory support with a BIPAP device were required to control disease activity and acute respiratory failure without unexpected side effects including infections.

\section{Case presentation}

A 59-year-old woman who had been diagnosed with hyperlipidemia and treated with $2.5 \mathrm{mg} /$ day of rosuvastatin calcium for 5 years stopped taking the drug 4 months before admission to our hospital due to elevation of creatine kinase (CK, $1200 \mathrm{U} / \mathrm{L}$; normal, 41-153 U/L). Withdrawal of rosuvastatin for 1 month did not decrease the level of CK (> $2000 \mathrm{U} / \mathrm{L}$ ), and she was admitted to our hospital due to the development of muscle weakness of her neck and bilateral upper extremities. Manual muscle testing (MMT) revealed marked muscle weakness of her neck and her paraspinal and bilateral upper extremities (proximal>distal) with normal muscle tone, reflexes but varying power (neck: 4, shoulder abductors: 4/4, elbow flexors: 4/4, elbow extensors: 4/4, wrist extensors: 5/4, hip flexors: $3 / 3$, knee extensors: $5 / 5$, knee flexors: $4 / 4$, ankle plantar flexors: 5/5). There was no evidence of neurological signs or symptoms of the cerebellar and autonomic systems. She had no skin rashes as exemplified by dermatomyositis. Laboratory data showed leukocytosis $(10,200 / \mu \mathrm{L}$; normal, 3300-8600/ $\mu \mathrm{L})$, increased serum levels of muscle enzymes including CK (2212 U/L), myoglobin (Mb, $2030 \mathrm{ng} / \mathrm{ml}$; normal, 18-70 $\mathrm{ng} / \mathrm{ml}$ ) and aldolase (58.1 U/L; normal, 2.7-7.5 U/L) and increased C-reactive protein (CRP) level $(1.17 \mathrm{mg} / \mathrm{dL}$; normal, <0.15 mg/dL) (Table 1). Tests for autoantibodies including antinuclear antibody, rheumatoid factor, anti-Ro/SSA antibody and anti-La/SSB antibody were negative, while disease-specific anti-HMGCR antibodies for necrotizing myopathy were positive (3.9 IU/ $\mathrm{mL}$ ) (Table 1). A computed tomography (CT) scan of the chest, abdomen, and pelvis showed no remarkable findings including infection, interstitial pneumonia and malignancy. Magnetic resonance imaging (MRI) showed high signal intensity on short-TI inversion recovery (STIR) T2-weighted imaging in the left biceps brachii muscle and triceps brachii muscle (Fig. 1a and b). A muscle biopsy from the right biceps brachii muscle showed a mixture of muscle fiber necrosis and regeneration without inflammatory cell infiltration (Fig. 1c-e). These findings suggested the existence of SANM. After admission and diagnosis, she received methylprednisolone pulse therapy (mPSL, $1 \mathrm{~g} /$ day $\times 3$ days, twice) and subsequent oral prednisolone therapy (PSL, $30 \mathrm{mg} /$ day) for 1 month, leading to improvement of her muscle weakness with reduction of the serum level of CK (449 U/L) (Fig. 1f). PSL was tapered to $25 \mathrm{mg} /$ day (for 1 month) and 22.5 $\mathrm{mg} /$ day (for $1 \mathrm{month}$ ) before tapering to $20 \mathrm{mg} /$ day.

One month after the PSL tapering to $20 \mathrm{mg} /$ day, her muscle weakness deteriorated with elevation of CK level (717 U/L) (Fig. 1f, Relapse) and oxygen desaturation (SpO2: 93\% at room air). Arterial blood gas analysis showed severe hypoxia and hypercapnia due to hypoventilation caused by weakness of respiratory muscles, and BIPAP was used for the management of acute respiratory failure in combination with IVIG $(20 \mathrm{~g} /$ day $\times 5$ days $)$ followed by mPSL pulse therapy $(1 \mathrm{~g} /$ day $\times 3$ days $)$, oral PSL $(30 \mathrm{mg} /$ day $\times 3$ weeks, then tapered to $25 \mathrm{mg} /$ day) and tacrolimus ( $3 \mathrm{mg} /$ day) (Fig. 1f and g). Twenty-seven days after the start of BIPAP, she was weaned from BIPAP with improvement of muscle weakness, hypoxemia and hypercapnia and reduction of the serum CK 
Table 1 Laboratory data of the patient on admission

\begin{tabular}{|c|c|c|c|c|c|c|c|c|}
\hline \multicolumn{3}{|c|}{ 【Hematology】 } & \multicolumn{3}{|c|}{ 【Blood chemistry】 } & \multicolumn{3}{|c|}{ 【Serological test】 } \\
\hline WBC & 10200 & $/ \mu \mathrm{L} \uparrow$ & $\mathrm{TP}$ & 6.4 & $\mathrm{~g} / \mathrm{dL} \downarrow$ & CRP & 1.17 & $\mathrm{mg} / \mathrm{dL} \uparrow$ \\
\hline Neutro. & 77.0 & $\% \uparrow$ & Alb & 3.6 & $\mathrm{~g} / \mathrm{dL} \downarrow$ & ESR & 22 & $\mathrm{~mm} / \mathrm{h} \uparrow$ \\
\hline Lymph. & 15.0 & $\% \downarrow$ & T. Bil & 0.64 & $\mathrm{mg} / \mathrm{dL}$ & KL-6 & 222 & $\mathrm{U} / \mathrm{mL}$ \\
\hline Mono. & 5.0 & $\%$ & AST & 111 & $U / L \uparrow$ & C3 & 113.6 & $\mathrm{mg} / \mathrm{dL}$ \\
\hline Eosino. & 1.0 & $\%$ & ALT & 210 & $\mathrm{U} / \mathrm{L} \uparrow$ & C4 & 31.9 & $\mathrm{mg} / \mathrm{dL} \uparrow$ \\
\hline $\mathrm{RBC}$ & $4.71 \times 10^{6}$ & $/ \mu \mathrm{L}$ & CK & 2212 & $\mathrm{U} / \mathrm{L} \uparrow$ & $\mathrm{CH} 50$ & 55 & $\mathrm{U} / \mathrm{mL} \uparrow$ \\
\hline $\mathrm{Hb}$ & 14.1 & $\mathrm{~g} / \mathrm{dL}$ & Myoglobin & 2030 & $\mathrm{ng} / \mathrm{mL} \uparrow$ & & & \\
\hline $\mathrm{Ht}$ & 44.3 & $\%$ & Aldolase & 58.1 & $\mathrm{U} / \mathrm{L} \uparrow$ & & & \\
\hline MCV & 94.0 & $\mathrm{fL}$ & ALP & 302 & $\mathrm{U} / \mathrm{L}$ & \multicolumn{3}{|c|}{ 【Immunological test】 } \\
\hline $\mathrm{MCH}$ & 30.0 & pg & yGTP & 22 & $U / L$ & $\mathrm{RF}$ & $<5.0$ & $\mathrm{IU} / \mathrm{mL}$ \\
\hline $\mathrm{MCHC}$ & 31.9 & $\mathrm{~g} / \mathrm{dL}$ & ChE & 229 & $\mathrm{U} / \mathrm{L}$ & ANA & $<0.08$ & Ratio \\
\hline \multirow[t]{11}{*}{ Plt } & $32.5 \times 10^{4}$ & $/ \mu \mathrm{L}$ & $\mathrm{LDH}$ & 1083 & $\mathrm{U} / \mathrm{L} \uparrow$ & Jo-1 & $<0.50$ & $\mathrm{U} / \mathrm{mL}$ \\
\hline & & & AMY & 113 & $U / L$ & ARS & $(-)$ & \\
\hline & & & BUN & 19.8 & $\mathrm{mg} / \mathrm{dL}$ & HMGCR & 3.9 & $\mathrm{IU} / \mathrm{mL} \uparrow$ \\
\hline & & & $\mathrm{Cr}$ & 0.45 & $\mathrm{mg} / \mathrm{dL} \downarrow$ & & & \\
\hline & & & UA & 4.5 & $\mathrm{mg} / \mathrm{dL}$ & & & \\
\hline & & & $\mathrm{Na}$ & 139 & $\mathrm{mmol} / \mathrm{L}$ & & & \\
\hline & & & $\mathrm{K}$ & 4.1 & $\mathrm{mmol} / \mathrm{L}$ & & & \\
\hline & & & $\mathrm{Cl}$ & 102 & $\mathrm{mmol} / \mathrm{L}$ & & & \\
\hline & & & $\mathrm{Ca}$ & 8.7 & $\mathrm{mg} / \mathrm{dL} \downarrow$ & & & \\
\hline & & & Ferritin & 128.1 & $\mathrm{ng} / \mathrm{mL}$ & & & \\
\hline & & & $\mathrm{HbA1c}$ & 6.9 & $\% \uparrow$ & & & \\
\hline
\end{tabular}

$C R P$ C-reactive protein, $R F$ rheumatoid factor, $A N A$ anti-nuclear antibodies, Jo-1 anti-Jo-1 antibodies, ARS anti-aminoacyl-tRNA synthetase antibodies, HMGCR anti-3hydroxy-3-methylglutaryl coenzyme A reductase antibodies

level (126 U/L) to a normal level (Fig. 1f and g). After she achieved remission, the dose of oral prednisolone was gradually tapered to $12.5 \mathrm{mg} /$ day without relapse for 3 months.

\section{Discussion}

During the course of the present case, we found that glucocorticoid monotherapy is not sufficient to control disease activity and that NIPSV is useful for the management of hypoxemia and hypercapnia observed in patients with SANM. SANM is classified as an autoimmuneassociated myopathy following abnormal production of anti-HMGCR autoantibodies after statin medications, different from well-established polymyositis/dermatomyositis-associated antibodies against aminoacyl-tRNA synthetases (ARS). Statin medications are one of the most common therapeutic strategies for hyperlipidemia to reduce morbidity and mortality for both cardiovascular and cerebral vascular diseases [1], whereas $5-20 \%$ of the patients stop taking a statin due to side effects including elevation of serum CK level regardless of the presence or absence of myalgia $[11,12]$. While statin-related myopathy is relieved after discontinuation of the statin in most cases, 2 or 3 of 100,000 statin-treated patients develop severe myopathy that displays proximal muscle weakness and/or muscle pain with elevation of CK level. It has been reported that anti-HMGCR antibodies could induce muscle weakness in mice through a complement-mediated mechanism [13]. However, the role of anti-HMGCR autoantibodies in the pathogenesis of SANM has not been clarified yet. Despite the presence of autoantibodies, necrotic and regenerating myofibers without inflammatory infiltrates are predominantly observed in SANM, indicating that the pathogenesis of SANM may be different from that of common inflammatory myopathy, polymyositis/dermatomyositis. Consistent with these findings, glucocorticoid monotherapy, which is initially used for polymyositis/ dermatomyositis, is not sufficient to control disease activity, and combination therapy of glucocorticoids and immunosuppressants is required for SANM [8, 14-16]. Other groups recommended triple therapy of glucocorticoids, immunosuppressants and IVIG [5] or rituximab [8] for SANM. Our case demonstrates that treatment with immunosuppressants and IVIG in addition to glucocorticoids is required for SANM patients complicated with hypoxemia and hypercapnia due to acute respiratory failure. Further studies are needed to determine the optimal treatment for patients with SANM.

In addition to the combination therapy, we used NIPSV to control respiratory failure caused by SANM. A previous study showed that half of the patients with proximal myopathy had more than 50\% reduction of both inspiratory and expiratory muscle strengths and 

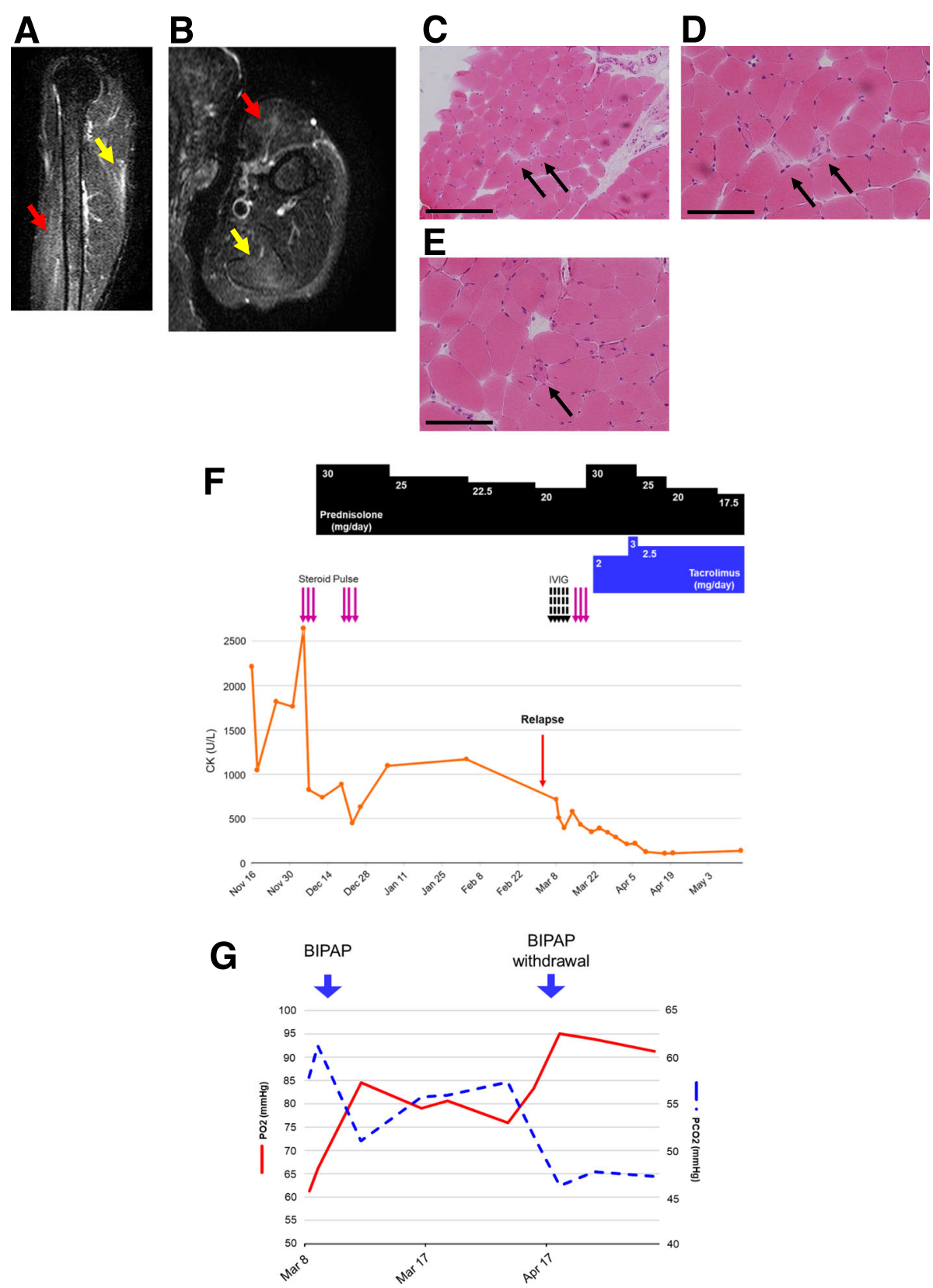

Fig. $\mathbf{1}$ a and $\mathbf{b}$ STIR T2-weighted imaging of MRI in the left proximal upper extremity (a sagittal imaging; $\mathbf{b}$ axial imaging). Red and yellow arrows indicate the left biceps brachii muscle and triceps brachii muscle, respectively. $\mathbf{c}$ and $\mathbf{d}$ H\&E staining at lower magnification (c) and higher magnification (d) of muscle biopsy from the right biceps brachii muscle. e Another field image of H\&E staining of the muscle biopsy from the same muscle. Scale bars: $200 \mu \mathrm{m}$ (c), $100 \mu \mathrm{m}$ (d and e). Black arrows indicate a mixture of muscle fiber necrosis and regeneration without inflammatory cell infiltration. $\mathbf{f}$ Clinical course of the patient showing serum levels of creatine kinase (CK, normal, 41-153 U/L). IVIG: intravenous immunoglobulin. $\mathbf{g}$ Clinical course of the patient showing severe hypoxia and hypercapnia due to hypoventilation caused by weakness of respiratory muscles. BIPAP was used for the management of acute respiratory failure, which dramatically improved after the commencement of BIPAP support

that hypercapnia was likely to occur when respiratory muscle strength and vital capacity were less than $30 \%$ of normal and $55 \%$ of the predicted value, respectively [17]. Previously, endotracheal intubation with a ventilator was a major therapeutic strategy in patients with acute respiratory failure who did not respond to conventional treatment such as medications and oxygen. In addition to complications related to the procedure of intubation including local trauma, gastric content aspiration and transient hypotension, intubated patients need complete 
sedation, resulting in limited communication and further muscle weakness. Moreover, those patients have a higher risk of pneumonia, leading to higher mortality [18]. On the other hand, a previous meta-analysis showed that NIPSV reduces the intubation rate and mortality by 50 and $40 \%$, respectively [18]. Therefore, NIPSV may be recommended to control hypoxemia and hypercapnia during the time before induction of remission and subsequent improvement of respiratory muscles in patients with SANM.

\section{Conclusion}

We reported a severe case of SANM complicated with respiratory failure caused by weakness of respiratory muscles. Our report provides new insights into the role of immunosuppressants and biphasic positive airway pressure for induction of remission in patients with SANM.

\section{Abbreviations}

HMGCR: 3-hydroxy-3-methylglutaryl coenzyme A reductase; BIPAP: Biphasic positive airway pressure; SANM: Statin-associated necrotizing myopathy; CK: Creatine kinase; NIPSV: Noninvasive pressure support ventilation; IPAP: Inspiratory positive airway pressure; EPAP: Expiratory positive airway pressure; IVlg: Intravenous immunoglobulins; Mb: Myoglobin; CRP: C-reactive protein; CT: Computed tomography; MRI: Magnetic resonance imaging; STIR: Short-TI inversion recovery; ARS: Aminoacyl-tRNA synthetases

\section{Acknowledgements}

NA

\section{Authors' contributions}

YY managed the patient, created the figure, collected laboratory data and formulated the table, and submitted the article. YM wrote the abstract, case report section, and discussion, completed edits, and did much of the literature review. KT, YO, KS1, TY, KA performed histological examination of the muscle biopsy and provided the figure images. MY managed the patient. KS2 and JW completed edits. All authors read and approved the final manuscript.

\section{Funding}

This work has no financial relationship.

\section{Availability of data and materials}

NA

\section{Ethics approval and consent to participate}

NA

\section{Consent for publication}

Written informed consent was obtained from the patient for publication of this case report and any accompanying images. A copy of the written consent is available for review by the Editor of this journal.

\section{Competing interests}

All of the authors declare that they have no competing interest.

\section{Author details}

'Department of Nephrology, Rheumatology, Endocrinology and Metabolism, Okayama University Graduate School of Medicine, Dentistry and Pharmaceutical Sciences, Okayama 700-8558, Japan. ${ }^{2}$ Department of Neurology, Okayama University Graduate School of Medicine, Dentistry and Pharmaceutical Sciences, Okayama 700-8558, Japan. ${ }^{3}$ Center for Rheumatology, Okayama Saiseikai General Hospital, Okayama 700-8511, Japan.
Received: 28 March 2019 Accepted: 20 May 2020

Published online: 03 June 2020

\section{References}

1. Sweidan AJ, Leung A, Kaiser CJ, Strube SJ, Dokukin AN, Romansky S, et al. A case of statin-associated autoimmune myopathy. Clin Med Insights Case Rep. 2017;10:1179547616688231.

2. Law M, Rudnicka AR. Statin safety: a systematic review. Am J Cardiol. 2006; 97:52C-60C

3. Mammen AL. Statin-associated autoimmune myopathy. N Engl J Med. 2016; 374:664-9.

4. Mirlesse N, Egervari K, Bornand A, Lecluse J, Lobrinus JA, Scheffler M, et al. Statin-induced autoimmune necrotizing myopathy with pharyngeal muscles involvement. Age Ageing. 2020;afaa038.

5. Kassardjian CD, Lennon VA, Alfugham NB, Mahler M, Milone M. Clinical features and treatment outcomes of necrotizing autoimmune myopathy. JAMA Neurol. 2015;72:996-1003.

6. Selva-O'Callaghan A, Alvarado-Cardenas M, Pinal-Fernandez I, TralleroAraguas E, Milisenda JC, Martinez MA, et al. Statin-induced myalgia and myositis: an update on pathogenesis and clinical recommendations. Expert Rev Clin Immunol. 2018;14:215-24.

7. Musset L, Allenbach Y, Benveniste O, Boyer O, Bossuyt X, Bentow C, et al. Anti-HMGCR antibodies as a biomarker for immune-mediated necrotizing myopathies: a history of statins and experience from a large international multi-center study. Autoimmun Rev. 2016;15:983-93.

8. Christopher-Stine L, Casciola-Rosen LA, Hong G, Chung T, Corse AM, Mammen AL. A novel autoantibody recognizing 200-kd and 100-kd proteins is associated with an immune-mediated necrotizing myopathy. Arthritis Rheum. 2010;62:2757-66.

9. Drouot L, Allenbach Y, Jouen F, Charuel JL, Martinet J, Meyer A, et al. Exploring necrotizing autoimmune myopathies with a novel immunoassay for anti-3-hydroxy-3-methyl-glutaryl-CoA reductase autoantibodies. Arthritis Res Ther. 2014;16:R39.

10. Hillberg RE, Johnson DC. Noninvasive ventilation. N Engl J Med. 1997;337: 1746-52.

11. Cholesterol Treatment Trialists C, Fulcher J, O'Connell R, Voysey M, Emberson J, Blackwell L, et al. Efficacy and safety of LDL-lowering therapy among men and women: meta-analysis of individual data from 174,000 participants in 27 randomised trials. Lancet. 2015;385:1397-405.

12. Bruckert E, Hayem G, Dejager S, Yau C, Begaud B. Mild to moderate muscular symptoms with high-dosage statin therapy in hyperlipidemic patients--the PRIMO study. Cardiovasc Drugs Ther. 2005;19:403-14.

13. Bergua C, Chiavelli H, Allenbach Y, Arouche-Delaperche L, Arnoult C, Bourdenet $G$, et al. In vivo pathogenicity of IgG from patients with anti-SRP or anti-HMGCR autoantibodies in immune-mediated necrotising myopathy. Ann Rheum Dis. 2019;78:131-9.

14. Hengstman GJ, ter Laak HJ, Vree Egberts WT, Lundberg IE, Moutsopoulos HM, Vencovsky J, et al. Anti-signal recognition particle autoantibodies: marker of a necrotising myopathy. Ann Rheum Dis. 2006;65:1635-8.

15. Werner JL, Christopher-Stine L, Ghazarian SR, Pak KS, Kus JE, Daya NR, et al. Antibody levels correlate with creatine kinase levels and strength in anti-3hydroxy-3-methylglutaryl-coenzyme a reductase-associated autoimmune myopathy. Arthritis Rheum. 2012;64:4087-93.

16. Kao AH, Lacomis D, Lucas M, Fertig N, Oddis CV. Anti-signal recognition particle autoantibody in patients with and patients without idiopathic inflammatory myopathy. Arthritis Rheum. 2004;50:209-15.

17. Braun NM, Arora NS, Rochester DF. Respiratory muscle and pulmonary function in polymyositis and other proximal myopathies. Thorax. 1983;38: 616-23.

18. Masip J. Non-invasive ventilation. Heart Fail Rev. 2007;12:119-24.

\section{Publisher's Note}

Springer Nature remains neutral with regard to jurisdictional claims in published maps and institutional affiliations. 